\title{
Wat als prostaatkanker in de familie voorkomt?
}

\author{
Ruben G. H. M. Cremers · Marco H. Blanker - Maaike M. Bloemendal
}

Published online: 11 February 2020

(C) The Author(s) 2020

Samenvatting In de algemene populatie geldt het advies om bij een verzoek om PSA-bepaling eerst de voors en tegens goed af te wegen, eventueel ondersteund door online tools, zoals te vinden zijn op https://www.thuisarts.nl/keuzehulpen/psa/. De familieanamnese is daarbij van belang voor het inschatten van een mogelijk erfelijk verhoogde kans op een agressieve prostaatkanker. Zowel het voorkomen als ook de mate van agressiviteit van de prostaatkankers dient daarbij uitgevraagd te worden, als ook tumoren die aan BRCA2-mutaties gerelateerd zijn (mammacarcinoom en ovariumcarcinoom bij vrouwelijke familieleden). Een (mogelijk) verhoogd erfelijk risico op agressieve prostaatkanker kan worden gebruikt om af te wijken van het algemene advies: bij eerstegraads verwanten van prostaatkankerpatiënten in HPC-families wordt tweejaarlijks PSA-onderzoek vanaf 50 jaar (of vanaf 5 jaar vóór de jongste prostaatkankerpatiënt in de familie) geadviseerd. Het vóórkomen van niet-agressieve prostaatkankers in de familie is biologisch gezien geen reden om af te wijken van het algemene advies ten aanzien van prostaatkankerscreening.

dr. R. G. H. M. Cremers ( $\square)$

afdeling Urologie, Deventer Ziekenhuis, Deventer, Nederland

ruben.cremers@dz.nl

dr. M. H. Blanker

afdeling Huisartsgeneeskunde en ouderengeneeskunde,

Universitair Medisch Centrum Groningen, Groningen,

Nederland

drs. M. M. Bloemendal

Twello, Nederland
Trefwoorden prostaatkanker - erfelijk prostaatkanker · familieanamnese - BRCA2 - PSA · screening

\section{What if prostate cancer runs in the family?}

Abstract In the general population, a PSA test should be preceded by a careful consideration of pros and cons and can be supported by online tools such as https://www.thuisarts.nl/keuzehulpen/psa/. Family history assessment is important to identify a possible increased hereditary risk of an aggressive prostate cancer. It should include both presence and aggressiveness of prostate cancers as well as tumours related to BRCA2-mutations (breast and ovarian cancer in female relatives). A confirmed or suspected hereditary risk of aggressive prostate cancer could be used to divert from the general prostate cancer screening advice; in first-degree relatives of prostate cancer patients in HPC families, two-yearly PSA testing is advised starting at 50 years of age (or at 5 years before the youngest age at diagnosis in the family). Familial occurrence of non-aggressive prostate cancers is not a biologically sound reason to divert from the general advice.

Keywords prostate cancer - hereditary prostate cancer · family history · BRCA2 - PSA · screening

\section{Introductie}

Prostaatkanker is de meest frequent gediagnosticeerde kanker bij Nederlandse mannen: momenteel krijgen jaarlijks ruim meer dan 12.000 Nederlandse mannen de diagnose prostaatkanker [1]. De introductie van PSA-bepalingen heeft in belangrijke mate bijgedragen aan een toename in de incidentie en prevalentie van prostaatkanker sinds het begin van 
dit millennium, terwijl de kans om te sterven aan prostaatkanker slechts gering afnam. Nederland kent geen populatiescreening naar prostaatkanker, omdat de Gezondheidsraad de nadelen van screening niet vindt opwegen tegen de voordelen $[2,3]$. Hoewel op PSA-gebaseerde screening resulteert in een relatieve mortaliteitsreductie ( $20 \%$ bij 16 jaar follow-up), is het aantal mannen dat gescreend $(n=570)$ en gediagnosticeerd dan wel eventueel behandeld $(n=18)$ moet worden om één sterfgeval te voorkomen onevenredig hoog [4]. Te meer omdat bij deze zeer beperkte sterftewinst de negatieve bijeffecten van de screening in ogenschouw moeten worden genomen, denk aan 'onterechte' onrust bij verhoogde PSA-waarden, ervaren stress als 'kankerpatiënt' wanneer geen behandeling wordt uitgevoerd (active surveillance) en de bijwerkingen van de behandelingen, met name incontinentie en seksuele problematiek. Ondertussen vragen mannen zelf om prostaatonderzoek, veelal bij hun huisarts [5]. Dat doen ze om verschillende redenen. Prostaatkanker in de familie is er daar een van, waarbij het invoelbaar is dat mannelijke familieleden gealarmeerd raken als bij een broer of vader prostaatkanker wordt vastgesteld. Huisartsen zullen bij deze groep wellicht sneller geneigd zijn om het verzoek om prostaatkankerscreening in te willigen dan is verwoord in de NHG-Standaard 'Mictieklachten bij mannen'. Daarin wordt terughoudendheid geadviseerd ten aanzien van screening en staat het geven van uitleg over voor- en nadelen van screening centraal [6].

In dit artikel zullen aan de hand van vier casus met verschillende mate van familiaire belasting de voors en tegens van onderzoek naar prostaatkanker worden besproken en de overwegingen die hierbij worden gemaakt. Ook wordt ingegaan op de rol van de familieanamnese, waarbij het in essentie draait om het (zo goed mogelijk) onderscheid maken tussen 'prostaatkanker in de familie' en 'erfelijk prostaatkanker' (hereditary prostate cancer; HPC).

\section{Overwegingen bij prostaatkankeronderzoek}

\section{Casus A: Familieanamnese onbekend}

Op uw spreekuur komt de heer A. van 55 jaar. Recent is een goede vriend van hem gediagnosticeerd met gemetastaseerd prostaatcarcinoom en A. vraagt zich af of het voor hem ook een goed idee is om zijn prostaat te laten controleren. A. heeft geen cardiopulmonale voorgeschiedenis en gebruikt geen medicatie. Hij heeft geen hinderlijke mictieklachten, al plast hij 'niet meer zoals toen hij 20 was en moet hij er eens een keertje vaker uit 's nachts'. A. is geadopteerd en heeft geen informatie over zijn biologische familie.

\section{Bespreking casus A}

Vanwege de centrale rol die de huisarts speelt in het Nederlandse zorgsysteem, zal de heer A. eerder door de huisarts herkend worden dan door de Nederlandse uroloog. Zowel huisarts als uroloog zal bij het geven van advies - als het goed is - de eerder genoemde NHG-Standaard volgen [6]. Deze schrijft voor om de heer A. te informeren over de mogelijkheden van controle op prostaatkanker door middel van serum-PSA en rectaal toucher, maar om tevens aan te geven wat de nadelen daarvan zijn. De huisarts (of uroloog) kan daarbij online tools gebruiken, zoals de risicocalculators op https://www.prostaatwijzer.nl en de PSAkeuzehulp op https://www.thuisarts.nl/keuzehulpen/ psa/. In december 2019 werd de keuzehulp aangepast en daarmee toegankelijker gemaakt voor gebruikers. Huisartsen en urologen kunnen verwijzen naar deze keuzehulp, zeker als binnen het consult door de patiënt nog geen keuze is gemaakt om het onderzoek wel of niet te laten verrichten. Doordat de familiegeschiedenis van de heer A. niet te achterhalen is, kan er geen inschatting gemaakt worden van een eventuele familiaire belasting. Dit voorbeeld lijkt vergezocht, maar toch komt het vaak voor dat een familiegeschiedenis maar beperkt bekend is. Denk aan een beperkt of zelfs geheel afwezig zijn van contact met de familie of een familie waarin niet (of niet in detail) over medische problemen gesproken wordt. In Nederland neemt daarnaast het aantal kinderen - en dus ook het aantal mannen per gezin - al decennia lang af, waarmee de kans op een naaste verwant met prostaatkanker ook afneemt. Van de mannen die met prostaatkanker worden gediagnosticeerd, heeft gemiddeld genomen ruim $20 \%$ minimaal één aangedane eerstegraads verwant met prostaatkanker [7].

Ervan uitgaande dat de heer A. - na zorgvuldige uitleg over de voors en tegens - ervoor kiest om zich te laten nakijken op prostaatkanker, zal er dus onder andere een serum-PSA bepaald worden. Doordat PSA niet prostaatkankerspecifiek is, is deze test - zoals al eerder uitgelegd - niet ideaal. Hoewel een hoger PSA-gehalte duidelijk samenhangt met een hogere kans op prostaatkanker, is er geen afkapwaarde die als bovengrens kan worden gebruikt om met zekerheid van de aanwezigheid van prostaatkanker te kunnen spreken, óf het PSA-gehalte is zo hoog dat er meteen een grote kans is op metastasen. Ook is er geen afkapwaarde die als ondergrens kan dienen, zodat je ook niet met zekerheid kunt zeggen dat er géén prostaatkanker aanwezig is. We zien onszelf hiermee gesteld voor een continue afweging tussen enerzijds een agressieve prostaatkanker op een zo vroeg mogelijk moment te willen vinden, maar anderzijds geen onnodige invasieve diagnostiek te willen verrichten. De strategie die momenteel gevolgd wordt met de afkapwaarde voor verwijzing van $3 \mathrm{ng} / \mathrm{ml}$ leidt onherroepelijk tot overdiagnostiek en overbehandeling [6]. Manieren om de interpretatie van PSA te verbeteren, zoals gebruik van de prostaatwijzers, hebben weliswaar meerwaarde bij het nemen van beslissingen over aanvullende diagnostiek, maar ze lossen de intrinsieke beperkingen van PSA niet op [8]. 
Desalniettemin hebben we momenteel geen betere gevalideerde tools om prostaatkanker vroeg te detecteren en vinden er veel PSA-bepalingen plaats. Zonder PSA zouden we, net als in de situatie tot en met de jaren 80 van de $20^{\mathrm{e}}$ eeuw, moeten afwachten tot de prostaatkanker palpabel wordt of zich uit in pijnklachten van metastasen. Ook nu nog presenteren zich regelmatig mannen in een vergevorderd stadium van de ziekte, bij wie genezing niet meer mogelijk is. Tot er een betere test is, is het zaak om met goede uitleg van de voor- en nadelen van de huidige mogelijkheden de nuance te vinden en de mannen zelf een goede beslissing te laten nemen over de vraag of ze een prostaatonderzoek willen.

\section{Casus B: Familieanamnese positief voor prostaatkanker, zonder aanwijzingen voor agressieve prostaatkanker}

De volgende patiënt op uw spreekuur is de heer B. Hij heeft recent op tv gehoord dat mannen zich moeten laten nakijken op prostaatkanker, vooral als prostaatkanker in de familie voorkomt. B. is 65 jaar en heeft twee oudere broers. Zijn oudste broer is vorig jaar met goed gevolg behandeld voor prostaatkanker door middel van brachytherapie. Zijn broer voelde niet voor een afwachtend beleid, hoewel B. weet dat dit wel aan zijn broer was voorgesteld. De heer B. weet met al die media-aandacht voor prostaatkanker nu niet meer zo goed of hij zijn prostaat wel of niet moet laten nakijken. Een aantal jaren geleden (ruim voor de diagnose bij zijn broer) besloot hij na overleg met zijn huisarts, die hem uitlegde dat er ook nadelen aan prostaatkankeronderzoek kunnen zitten, om geen PSA te laten bepalen.

\section{Bespreking casus B}

Mannen met een familielid met prostaatkanker bezoeken vaker een huisarts en/of uroloog. Op het eerste gezicht lijkt dat terecht: een positieve familieanamnese met prostaatkanker is een van de bekende risicofactoren voor prostaatkanker met een tweemaal zo groot risico voor zonen en een driemaal zo groot risico voor broers van prostaatkankerpatiënten [9]. In het geval van de heer $\mathrm{B}$. is het echter maar de vraag of de oudere broer met een niet-agressieve prostaatkanker betekent dat de heer B. een hoger risico heeft op een significante prostaatkanker.

Ervan uitgaande dat de oudere broer daadwerkelijk een niet-agressieve prostaatkanker heeft gehad en dat deze op de gebruikelijke manier met PSA-metingen, rectaal toucher, prostaatbiopten en een MRI-scan is aangetoond, heeft deze broer eigenlijk juist laten zien dat hij géén agressieve prostaatkanker heeft. Het vinden van deze prostaatkanker is daarmee in ieder geval op geen enkele wijze een aanwijzing voor de veronderstelling dat de heer B. een erfelijk verhoogd risico op een agressieve prostaatkanker heeft. Integendeel zelfs, deze situatie kan goed worden geïnterpreteerd als een aanwijzing voor de veronderstelling dat de heer $\mathrm{B}$. hierdoor juist meer risico loopt op overdiagnostiek en -behandeling, aangezien hij door de ervaringen van zijn broer mogelijk sneller zal kiezen voor een behandeling van een laag-risicoprostaatkanker, mocht die bij hem worden gevonden [10].

De misschien nog belangrijkere vraag is: als de broer van de heer $B$. gediagnosticeerd was met een gemetastaseerd prostaatcarcinoom, zou het advies dan anders worden? Daarvoor is het belangrijk om in te schatten wat de kans is dat er een erfelijke oorzaak is voor de prostaatkanker in de familie. Daartoe beschouwen we eerst de volgende casus.

\section{Casus C: Erfelijke prostaatkanker}

De heer C. is uw volgende patiënt. Hij is net 50 jaar geworden en zijn vader en drie ooms (broers van vader) zijn gediagnosticeerd met prostaatkanker (allen kort na elkaar tussen hun $60^{\mathrm{e}}$ en $70^{\mathrm{e}}$ jaar; zijn vader en één oom zijn inmiddels overleden ten gevolge van prostaatkanker). Hij is zelf de oudste van drie broers. De heer C. heeft via de klinisch geneticus van een van zijn ooms een advies gekregen om zich te laten onderzoeken op prostaatkanker.

\section{Bespreking casus C}

Bij gebrek aan bekende hoog-penetrante genen die leiden tot prostaatkanker wordt 'erfelijk prostaatkanker' vooralsnog gedefinieerd op basis van het vaak voorkomen van prostaatkanker in de familie. Hereditary prostate cancer (HPC) wordt gedefinieerd als: 1) drie of meer familieleden met prostaatkanker van wie één persoon een eerstegraads familielid is van de andere twee; 2) twee of meer eerstegraads familieleden met prostaatkanker met een diagnoseleeftijd $<55$ jaar; 3) prostaatcarcinoom vastgesteld in drie opeenvolgende generaties, binnen één tak van de familie (fig. 1). Niet-aangedane eerstegraads familieleden van patiënten met prostaatkanker in deze families worden actief geadviseerd om zich te laten screenen [11]. In Nederland heeft de Stichting Opsporing Erfelijke Tumoren (StOET; http://www.stoet.nl) de Nederlandse HPC-families uit de periode 1995-2010 in kaart gebracht en tot eind 2019 adviezen verzorgd voor gerichte prostaatkankerscreening in deze families [12]. Momenteel worden er geen nieuwe families meer toegevoegd aan de registratie.

Het is de vraag of het hanteren van de HPC-criteria de beste manier is om de juiste families met een erfelijk verhoogd risico op agressieve prostaatkankers te identificeren. Uit onderzoek naar de aard van de prostaatkankers in de Nederlandse HPC-families bleek namelijk dat de kans op het vinden van niet-significante prostaatkanker groter was bij patiënten die niet als eerste in de familie gediagnosticeerd waren (eigen onderzoek StOET-gegevens). Daarmee hadden HPC-patiënten gemiddeld genomen vaker niet-significante prostaatkankers, maar ondergingen 
Figuur 1 Diagnostische criteria erfelijk prostaatkanker (hereditary prostate cancer; HPC). 1 Prostaatcarcinoom vastgesteld bij $\geq 3$ naaste familieleden (eerste- of tweedegraads verwanten). 2 Prostaatcarcinoom vastgesteld bij $\geq$ 2 eerste- of tweedegraads verwanten, met een diagnoseleeftijd van 55 jaar of jonger. 3 Prostaatcarcinoom vastgesteld in drie opeenvolgende generaties, binnen één tak van de familie
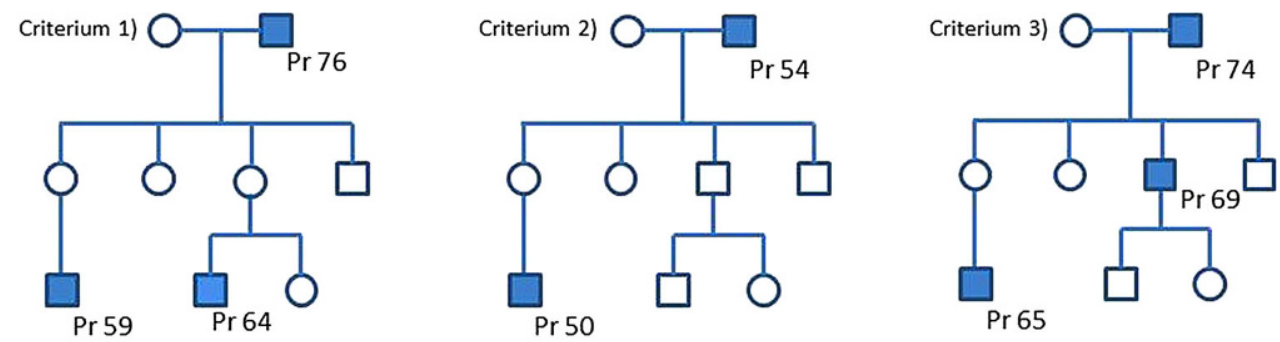

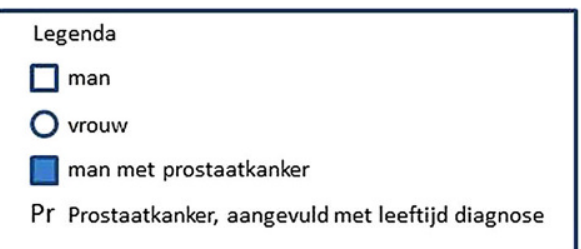

zij vaker dan mannen met 'sporadisch' (niet-erfelijk) prostaatkanker invasieve behandelingen [13]. Ook leken de mannen in de HPC-families genetisch gezien opvallend veel op mannen met sporadisch prostaatkanker [14]. Dit kan gezien worden als een aanwijzing voor de veronderstelling dat er maar bij weinig HPCmannen sprake was van een daadwerkelijk erfelijk verhoogd risico op prostaatkanker. Het is ook een steekhoudende aanwijzing voor de veronderstelling dat mannen met prostaatkanker in de familie vaker op eigen initiatief naar de arts zijn gegaan, waardoor juist veel niet-agressieve prostaatkankers zijn gevonden. Hiermee lopen mannen met een aangedaan familielid misschien zelfs meer risico op overdiagnostiek en overbehandeling dan andere mannen.

In voorkomende gevallen, zoals bij de heer C., zal het echter evident zijn dat in een familie een verhoogd risico bestaat op agressieve prostaatkanker en dan geldt het advies om verwijzing naar een polikliniek Genetica te overwegen, zodat de familie in kaart kan worden gebracht. Bij de heer C. komt er niet alleen prostaatkanker bij liefst vier bloedverwanten voor (een eerstegraads en drie tweedegraads familieleden), bij zijn vader en oom verliepen de prostaatkankers ook nog eens zeer agressief, waardoor zij aan de ziekte zijn overleden. De heer C. krijgt daarom het advies om zich - wanneer hij dat wil - regelmatig te laten controleren (vanaf zijn 50e eenmaal per twee jaar) op prostaatkanker [12].

Het is uiteraard niet zeker dat de heer C. een verhoogd erfelijk risico heeft op prostaatkanker. Een dergelijke familiegeschiedenis kan ook verklaard worden door een combinatie van een aantal laag-risicovarianten (single nucleotide polymorphisms; SNP's), hoewel hiervoor nog geen gevalideerde tests beschikbaar zijn. Uitgaande van een hoog-risicomutatie (mutaties die meestal autosomaal dominant overerven) bij zijn vader en ooms, zou hij een kans hebben van $50 \%$ op de pathogene mutatie en alleen in dat geval zou hij een verhoogd risico hebben op prostaatkanker. $\mathrm{Er}$ zijn enkele hoog-risicomutaties bekend in onder andere het HOXB13- en vooral BRCA2-gen die kunnen leiden tot agressieve prostaatkanker. Een uitbreiding van de familieanamnese naar de aanwezigheid van andere aan BRCA2-gerelateerde tumoren (met name mamma- en ovariumcarcinoom bij de vrouwen in de paternale lijn van de familie) zou een indicatie kunnen geven van een erfelijke aandoening in de familie én ook relevant kunnen zijn voor de vrouwelijke verwanten. De bevestiging of een BRCA2- (of een andere hoog-risico)mutatie in de familie en bij het individu zelf aanwezig is, kan dan (via onderzoek door een klinisch geneticus) worden uitgezocht en vertaald worden in gerichte adviezen.

\section{Casus D: Familieanamnese positief voor prostaatkanker, duidelijke aanwijzingen voor agressieve prostaatkanker}

De situatie van de heer D. is gelijk aan die van de heer B., alleen is de oudere broer van de heer D. niet genezen van prostaatkanker, maar na een vrij kort traject met hormoonbehandeling overleden aan een snel progressieve prostaatkanker.

\section{Bespreking Casus D}

Voor mannen in de Nederlandse algemene populatie is er een welomschreven, in essentie restrictief beleid ten aanzien van prostaatkankerscreening. Dat is de ene kant. Aan de andere kant van het spectrum is er voor mannen met een bekend of sterk vermoed erfelijk verhoogd risico op agressief prostaatkanker ook een duidelijk beleid: vanaf 50 jaar (of vanaf 5 jaar voor de leeftijd bij diagnose van de jongste patiënt in de familie indien $<50$ jaar) screenen door middel van een tweejaarlijks PSA-bepaling [12].

Voor mannen met een beperktere positieve familieanamnese voor prostaatkanker is het advies minder eenduidig, of ze zich nu in een situatie zoals in casus B of zoals in casus D bevinden. Hoewel broers 
van prostaatkankerpatiënten een ongeveer 2-3 keer verhoogd risico hebben om zelf gediagnosticeerd te worden met prostaatkanker, blijkt uit onderzoek in de HPC-families echter dat de mannen die niet als eerste in de familie prostaatkanker kregen, vaker dan gemiddeld niet-agressieve tumoren hebben. Bovendien hebben niet-aangedane mannen in HPC-families in een screeningsonderzoek eerder een verlaagd dan een verhoogd risico op prostaatkanker. En dat terwijl bij deze mannen juist een erfelijk verhoogd risico verwacht werd [15].

Aangezien er zelfs in deze groep mannen in HPCfamilies geen verhoogd risico op prostaatkanker wordt gevonden, is het maar zeer de vraag in hoeverre één verwant met prostaatkanker een goed selectiecriterium is om af te wijken van het advies dat geldt voor de algemene populatie. Het lijkt nog verdedigbaar om een positieve familieanamnese met agressieve prostaatkanker (casus D) te beschouwen als een indicator voor een verhoogd erfelijk risico op agressief prostaatkanker. Aan mannen die met een PSA-screeningsverzoek komen en een dergelijke familieanamnese hebben, kan worden uitgelegd dat hun risico op agressief prostaatkanker mogelijk groter is dan gemiddeld. Daarmee wordt de afweging die gemaakt kan worden in de PSA-keuzehulp (https://www.thuisarts.nl/ keuzehulpen/psa/) niet essentieel anders, maar verschuiven de accenten bij de interpretatie daarvan wel, omdat er bij meerdere agressieve prostaatkankers in de familie verwijzing naar een klinisch geneticus moet worden overwogen. Dit laatste geldt ook voor het geclusterd voorkomen van aan BRCA2-mutaties gerelateerde tumoren bij vrouwen in de familie, met name mammacarcinoom en ovariumcarcinoom.

\section{Conclusies voor de praktijk}

- Het aanwezig zijn van niet-agressieve prostaatkankers in de familie is biologisch gezien geen reden om af te wijken van het algemene advies ten aanzien van prostaatkankerscreening. Hier geldt dus in principe het algemene advies dat terughoudendheid met PSA-onderzoek geboden is en dat de voors en tegens van dit onderzoek goed tegen elkaar moeten worden afgewogen. Hoewel dit advies al de nodige tijd op deze manier in de richtlijnen staat, heeft $25 \%$ van de Nederlandse mannen ouder dan 40 jaar in de afgelopen vijf jaar zijn PSA laten controleren. In de leeftijdscategorie boven de 65 jaar is dat zelfs ruim $40 \%$ [16]. Totdat we de beschikking krijgen over een betere, vergelijkbaar of minder invasieve, gevalideerde test, zullen huisartsen en urologen in dit soort gevallen gezamenlijk de indicaties voor het gebruik van PSA-onderzoek in goede banen moeten leiden.

- Het gedetailleerd uitvragen van de familieanamnese is van belang bij het inschatten van de kans op een erfelijk bepaalde agressieve prostaatkanker. Daarbij dient zowel het voorkomen als ook de mate van agressiviteit van de prostaatkankers uitgevraagd te worden.

- Ook tumoren die aan BRCA2-mutaties gerelateerd zijn (mammacarcinoom en ovariumcarcinoom bij vrouwelijke familieleden) kunnen een aanwijzing zijn voor een erfelijk verhoogd risico op prostaatkanker. Een mogelijk verhoogd erfelijk risico op agressief prostaatkanker kan worden gebruikt om af te wijken van het algemene advies om terughoudend te zijn met PSA-onderzoek; bij eerstegraads verwanten van prostaatkankerpatiënten in HPCfamilies wordt tweejaarlijks PSA-onderzoek vanaf 50 jaar (of vanaf 5 jaar vóór de jongste prostaatkankerpatiënt in de familie) geadviseerd.

Open Access This article is distributed under the terms of the Creative Commons Attribution 4.0 International License (http://creativecommons.org/licenses/by/4.0/), which permits unrestricted use, distribution, and reproduction in any medium, provided you give appropriate credit to the original author(s) and the source, provide a link to the Creative Commons license, and indicate if changes were made.

\section{Literatuur}

1. Nederland IK. Incidentie prostaatkanker 2018. 2018. https://www.iknl.nl/nkr-cijfers. Geraadpleegd op: 15 januari2020.

2. Gezondheidsraad. Wet bevolkingsonderzoek: een beslishulp bij prostaatkankerscreening 2010. 2010. https:/ / www. gezondheidsraad.nl/documenten/adviezen/2010/04/28/ wet-bevolkingsonderzoek-een-beslishulp-bij-

prostaatkankerscreening-1. Geraadpleegd op: 15 januari2020.

3. Gezondheidsraad. WBO: onderzoek naar screening op prostaatkanker2018. 2018. https://www.gezondheidsraad. $\mathrm{nl} /$ documenten/adviezen/2018/11/27/wbo-onderzoeknaar-screening-op-prostaatkanker. Geraadpleegd op: 15 januari2020.

4. Hugosson J, Roobol MJ, Mansson M, Tammela TLJ, Zappa M, Nelen V, et al. A 16-yr follow-up of the European Randomized Study of Screening for Prostate Cancer. Eur Urol. 2019;76(1):43-51.

5. Meer S van der, Kollen BJ, Hirdes WH, Steffens MG, Hoekstra-Weebers JE, Nijman RM, et al. Impact of the European Randomized Study of Screening for Prostate Cancer (ERSPC) on prostate-specific antigen (PSA) testing by Dutch general practitioners. BJU Int. 2013;112(1):26-31.

6. Blanker MH, Breed SA, van der Heide WK, Norg RJC, de Vries A, Wolters RJ, et al. NHG-Standaard Mictieklachten bij mannen. Huisarts Wet. 2014;3(56):114-22. Actualisering bijlage in Oktober 2014;10(57):538.

7. Gudmundsson J, Sulem P, Gudbjartsson DF, Blondal T, Gylfason A, Agnarsson BA, et al. Genome-wide association and replication studies identify four variants associated with prostate cancer susceptibility. Nat Genet. 2009;41(10):1122-6.

8. Roobol MJ, van Vugt HA, Loeb S, Zhu X, Bul M, Bangma CH, et al. Prediction of prostate cancer risk: the role of prostate volume and digital rectal examination in the ERSPC risk calculators. Eur Urol. 2012;61(3):577-83.

9. Kicinski M, Vangronsveld J, Nawrot TS. An epidemiological reappraisal of the familial aggregation of prostate cancer: a meta-analysis. Plos One. 2011;6(10):e27130. 


\title{
Hier staat een advertentie.
}

\author{
cC bohn \\ stafleu \\ van loghum
}

Houten 2020 


\title{
Hier staat een advertentie.
}

\author{
cC bohn \\ stafleu \\ van loghum
}

Houten 2020 
10. Kinsella N, Stattin P, Cahill D, Brown C, Bill-Axelson A, Bratt $\mathrm{O}$, et al. Factors influencing men's choice of and adherence to active surveillance for low-risk prostate cancer: a mixed-method systematic review. Eur Urol. 2018;74(3):261-80.

11. Carter BS, Bova GS, Beaty TH, Steinberg GD, Childs B, Isaacs WB, et al. Hereditary prostate cancer: epidemiologic and clinical features. J Urol. 1993;150(3):797-802.

12. Vasen HFA, Hes FJ, Jong MM de. Erfelijke tumoren: richtlijnen voor diagnostiek en preventie. 6e druk. Leiden: Stichting Opsporing Erfelijke Tumoren (StOET); 2017.

13. Cremers RG, Aben KK, van Oort IM, Sedelaar JP, Vasen HF, Vermeulen $\mathrm{SH}$, et al. The clinical phenotype of hereditary versus sporadic prostate cancer: HPC definition revisited. Prostate. 2016;76(10):897-904.

14. Cremers RG, Galesloot TE, Aben KK, van Oort IM, Vasen HF, VermeulenSH, etal. Known susceptibilitySNPsfor sporadic prostatecancershowasimilar association with "hereditary" prostate cancer. Prostate. 2015;75(5):474-83.

15. Kiemeney LA, Broeders MJ, Pelger M, Kil PJ, Schroder FH, Witjes JA, et al. Screening for prostate cancer in Dutch hereditary prostate cancer families. Int J Cancer. 2008;122(4):871-6.

16. Leefstijl, preventief onderzoek; geslacht en leeftijd; 2010-2013: CBS. 2015. https://opendata.cbs.nl/statline/\#/ CBS/nl/. Geraadpleegd op: 15 januari 2020, updated 8 april 2015.

dr. Ruben G.H.M. Cremers, uroloog, epidemioloog

dr. Marco H. Blanker, huisarts-epidemioloog, universitair hoofddocent

drs. Maaike M. Bloemendal, waarnemend huisarts 